Article

\title{
Summative Assessment (Written) in Undergraduate Physiology Curriculum in Bangladesh: Reflection of Educational Objective
}

\author{
Ali $\mathrm{T}^{1}$, Begum $\mathrm{N}^{2}$, Begum AA ${ }^{3}$, Shamim KM${ }^{4}$, Ferdousi $\mathrm{S}^{5}$, Bennoor $\mathrm{KS}^{6}$
}

Background: A new curriculum for undergraduate medical education has been introduced for all universities in Bangladesh since 2002. It is expected that this new curriculum will improve the qualitative level of medical education. According to this curriculum the assessment system for the students has also been modified. This new scheme gives more emphasis on certain evaluation procedures in written examination to be customized. For example, short essay questions (SEQ) are preferred to long descriptive and short answer questions (SAQ). Questions should be specific answer oriented and targeted towards assessing the level of cognitive domain of the examinees.

Objective: The present retrospective analysis was done to observe the qualitative status in the written assessment procedure in Undergraduate Physiology after the implementation of the new curriculum by comparing the setting of the different question types under new curriculum with that of the old curriculum. This study was done also to identify the areas that warrant modification.Methods: This study analyzed all new and old curriculum based written questions of the assessment examinations (except MCQ) for undergraduate Physiology course from 2001 to 2006, under 4 different universities in Bangladesh. In total 63 question papers on physiology were included for evaluation. Data were statistically analyzed by proportion test using SPSS software.Results: The analysis indicates that there are significant improvement in type of questions (SEQ, SAQ and combined) and language (specific vs. non specific) field. However improvement in all the fields of medical education was statistically insignificant.Conclusion: Therefore, it may be concluded that the question setting procedure of the written examination according to the modern assessment technique has partially fulfilled

J Bangladesh Soc Physiol.2008 Dec;(3):61-65. For author affiliations, see end of text.

http://www.banglajol.info/index.php/JBSP

\section{Introduction:}

A great alteration has been occurred in the attitude and style in the medical education worldwide to make it more motivated and time oriented. ${ }^{1}$ In 1988 , world conference on medical education in Edinbergh ${ }^{2}$ gave emphasis on a national health priority based curriculum, community oriented educational settings, self directed student centered active learning and use of assessment technique ensuring achievement of professional competence and social values.

J Bangladesh Soc Physiol. 2008 Dec;(3):61-65
To meet the global need of these objectives changes in medical course curriculum and assessment technique became essential in Bangladesh. In this country a set up for undergraduate medical education was continued from the preliberation period up to 1988 . Then a great change was brought in curriculum in 1988 by making it more community oriented ${ }^{3}$.

Although, it was a combined product of reorientation of medical education (ROME) and community oriented medical education (COME) 
Article

but a thoroughly revised new curriculum for undergraduate course in medicine was implemented in 2002 in Bangladesh aiming at qualitative improvement in medical education ${ }^{4}$.

This new problem oriented curriculum for undergraduate medical education was introduced following the recommendations of medical educationist and it was approved by Bangladesh Medical and Dental Council ${ }^{4}$.

Assessment is a very important component of medical course curriculum. Medicine itself is a profession in which accurate and responsible assessment is of cardinal requirement. The assessment procedures have a powerful influence over learning process ${ }^{5}$. Scientific studies confirmed that it is the evaluation system rather than the educational objectives or curriculum or instructional techniques that have the most profound impact on what the students ultimately learn ${ }^{6}$. As study of the whole curriculum is laborious and time consuming, Rotem in 1982 showed an easy approach to review curriculum that was based on analysis of examination system ${ }^{7}$. Modern assessment technique prescribed in the new curriculum in Bangladesh includes Short Answer Question (SAQ and Multiple Choice Question (MCQ) for written aptitude 4 .

In the past, long essay questions were commonly used in written section of examination to assess the cognitive ability of students. But these traditional essay questions could not yield the expected answers and wide variation in student's interpretation was noted. Therefore, it showed limited validity, poor reliability and less objectivity $^{\mathbf{8}}$. On the other hand, wording in SEQ limits the scope of the content and directs the student towards a precise and specific response that makes it more reliable and valid ${ }^{8}$. In addition SAQ carries greater objectivity and reliability and their range of subject areas testes is extended ${ }^{9}$.

Very few study focusing assessment technique in undergraduate Physiology in Bangladesh has
Summative Assessment in Physiology

been carried out. One comparative study on SOE $^{1}$ and another on OSPE ${ }^{10}$ are available. But no published data on written assessment technique in undergraduate physiology has been reported in Bangladesh. Therefore, the present retrospective analysis was done to observe the qualitative status in the written assessment procedure in Undergraduate Physiology after the implementation of the new curriculum by comparing the setting of the different question types under new curriculum with that of the old curriculum. This study was done also to identify the areas that warrant modification.

\section{Methods:}

Total eighty five question papers for written examination in Physiology in First Professional Examinations held under Dhaka, Chittagong, Rajshahi, Shahjalal University from January 2001 to July 2008 were collected. Under old curriculum 57 question papers and under new curriculum 28 question papers were studied. They were grouped as Gr I (New curriculum) and Gr II (Old curriculum). Both the groups were again sub grouped as A (Dhaka University), B (Chittagong University), C (Rajshahi University), $\mathrm{D}$ (Shahjalal University). All the questions were categorized into recall, understanding, problem based, combined and uncategorized according to their assessing power. Again, the questions were marked as SAQ, SEQ, combined according to answer length and specific, nonspecific, combined according to forms of their language. All these different types of questions were expressed in percentage out of the total questions in new and old curriculum under individual university. Data were analyzed statistically by proportion Z test.

\section{Result:}

In the question papers under new curriculum of all Universities, percentage of SAQ was higher and percentage of SEQ was lower compared to old curriculum. But this difference were not statistically significant (Figure 1).

J Bangladesh Soc Physiol. 2008 Dec;(3):61-65 
In the question papers under new curriculum of all Universities percentage of SAQ was higher compared to old curriculum. But this differences were not statistically significant (Figure 1).

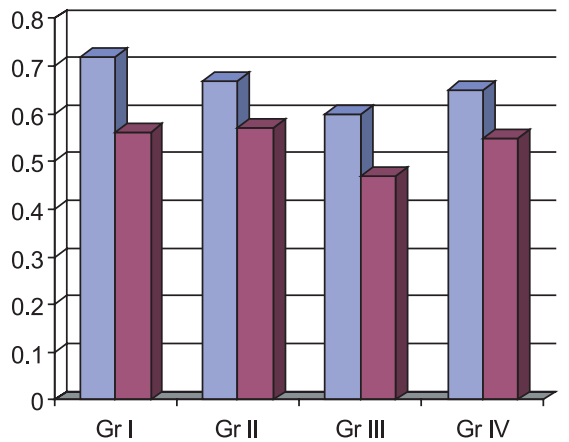

Figure: 1 Proportions of SAQ of both the curriculums of different universities

In all Universities the recall type of questions were decreased in new curriculum question papers in comparison to those of old except in Shahjalal. But this difference was not statistically significant (Figure 2).

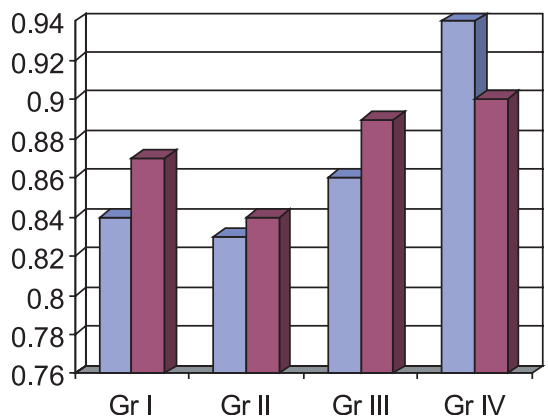

$\square$ New $\square$ Old

Figure: 2 Proportions of Recall type of questions of both the curriculums of different universities

Inclusion of problem based questions in Dhaka and Chittagong Universities was a notable finding in the new curriculum question papers (Figure 3).

Again percentage of specific type question was increased whereas non specific type was decreased in the question papers under new curriculum in all the universities when compared to old curriculum. But these changes were also not statistically significant (Figure 4).

J Bangladesh Soc Physiol. 2008 Dec;(3):61-65

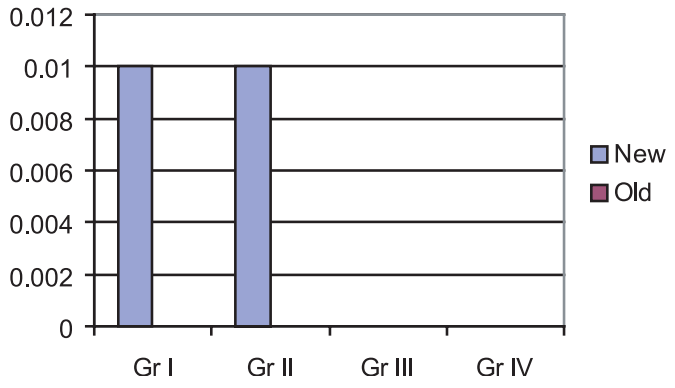

Figure: 3 Proportions of Problem based questions of both the curriculums of different universities

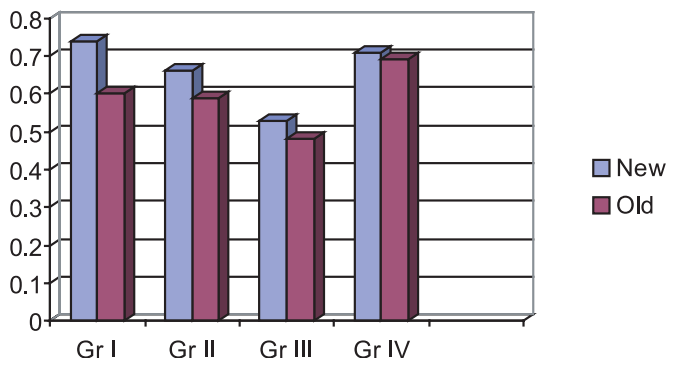

Figure: 4 Proportions of Specific type of questions of both the curriculums of different universities

Table - I

Proportions of different types of questions of both the curriculums of all universities $(n=)$

\begin{tabular}{lccc}
\hline Variables & $\begin{array}{c}\text { New } \\
\text { curriculum }\end{array}$ & $\begin{array}{c}\text { Old } \\
\text { curriculum }\end{array}$ & $\begin{array}{c}\mathrm{p} \\
\text { value }\end{array}$ \\
\hline SAQ & 0.66 & 0.54 & $1.33^{\mathrm{ns}}$ \\
SEQ & 0.37 & 0.46 & $1^{\mathrm{ns}}$ \\
Combined & 0 & 0 & $0^{\mathrm{ns}}$ \\
Recall & 0.87 & 0.88 & $0.17^{\mathrm{ns}}$ \\
Understanding & 0.13 & 0.09 & $0.68^{\mathrm{ns}}$ \\
Problem based & 0.01 & 0 & $1^{\mathrm{ns}}$ \\
Combined & 0 & 0 & $0^{\mathrm{ns}}$ \\
Specific & 0.66 & 0.64 & $0.22^{\mathrm{ns}}$ \\
Non specific & 0.39 & 0.45 & $0.622^{\mathrm{ns}}$ \\
Combined & 0 & 0 & $0^{\mathrm{ns}}$ \\
\hline
\end{tabular}




\section{Article}

\section{Discussion}

The present study was done to observe the status of the qualitative pattern of the written question paper setting of the new undergraduate medical curriculum and to compare it with that of the traditional one. While analyzing the written question papers of Undergraduate Physiology course of the present curriculum in Bangladesh, the basic problem faced was lacking of the objective of this course in the terms of amount of different types of questions, or how much component of the questions should be of different levels of cognitive domain, or different types of languages ${ }^{4}$. There should be fixed criteria as written document for setting questions for the written examinations that fulfill the objectives of the course. The finding of this study reveals that, there is an increase in understanding and specific type of questions in the new curriculum question papers. Along with this a decline in the amount of recall and non-specific type of questions are also observed, though the change was nonsignificant. Again, increase in the amount of short answered questions (SAQ), decrease in short essay questions (SEQ) and absence of long essay questions in the ongoing curriculum in comparison to the older one. This observation has accomplished the task, though partially, to achieve the target of modern assessment technique in written question paper setting. Unfortunately no data was available to compare these findings.

However, when the question papers under new curriculum were compared among the four different universities, there was an increase in the frequency of understanding type of questions in three universities than those of Shahjalal and the difference was significant $(\mathrm{p}<0.001)$. Again, the addition of problem based questions in the Physiology Written question papers of Dhaka and Chittagong Universities in comparison to Rajshahi and Shahjalal, indicates wide variation in question paper setting among different universities.
Summative Assessment in Physiology

It is important to note that the different variables of written assessment used in the question papers under the present study is similar to the methods adopted by the few investigators of our country 12,13 but the scoring system is different.

Therefore, it may be concluded that the question setting procedure of the written examination according to the modern assessment technique has partially fulfilled.

So, it may be recommended that, proper orientation and implementation of the evaluators and educators are imperative to get the desired benefit from the present undergraduate Physiology written assessment system.

\section{Author Affiliations}

1. *Taskina Ali, Assistant Professor of Physiology, BSMMU, Shahbag, Dhaka, Bangladesh.

2. Noorzahan Begum, Chairman \& Professor of Physiology, BSMMU, Shahbag, Dhaka, Bangladesh.

3. Anjuman Ara Begum, Assistant Professor of Anatomy, Rangpur Medical College, Rangpur, Bangladesh.

4. Khandaker Manzare Shamim, Chairman \& Professor of Anatomy, BSMMU, Shahbag, Dhaka, Bangladesh.

5. Sultana Ferdousi, Assistant Professor of Physiology, BSMMU, Shahbag, Dhaka, Bangladesh.

6. Kazi Saifuddin Bennoor, Assistant Professor of Respiratory Department, National Institute of Diseases of Chest \& Hospital (NIDCH), Mohakhali, Dhaka, Bangladesh.

* For Correspondence

\section{References}

1. Ferdousi S, Latif SA, Ahmed MM, Nessa A. Summative Assessment in Undergraduate Medical Student's Performance in physiology by structured Oral Examination. Mymensingh Med J, 2007, Jan; 16(1): 64-69.

2. Gracia Barbero M. Medical education in the light of the World health Organisation. Health for All strategy and European Union. Medical education, 1995, Jan, 29(1): 3-12.

3. Karim A, Haque M. Assessment system in Pharmacology-Does it reflect educational objectives and community health needs? Bangladesh J Physiol Pharmacol, 1996, July, 12(2): 65-67.

J Bangladesh Soc Physiol. 2008 Dec;(3):61-65 
4. Curriculum for Under-graduate Medical Education In Bangladesh 2002. Approved by Bangladesh Medical \& Dental Council.

5. Miller G E. assessments in Medical School. Med Educ 1976; 10: 79-80

6. Miller G E. Educational Strategies for the Health Professions. In: Developments of Educational Programmes for the Health Professionals WHO Public Health papers No. 52, 1973.

7. Rotem A, Barrand J, Azman A. analysis of examination in curriculum review. Medical education, 1982, 16: 3-6.

8. Paul VK. Essay Questions. In: Sood R, Paul VK, Sahni P, Mittal S, Kharbandra OP, Adkoli BV. editors. Assessments in Medical Education, trend and tools. New Delhi: K. L. Wig Centre for Medical Education and Technology, 1995, p 17-25.

9. Sabherwal U. Short Answered Questions. In: Sood R, Paul VK, Sahni P, Mittal S, Kharbandra OP, Adkoli
BV. editors. Assessments in Medical Education, trend and tools. New Delhi: K. L. Wig Centre for Medical Education and Technology, 1995, p 27-31.

10. Rahman N, Ferdousi S, Hoq N, Amin R, Kabir J. Evaluation of Objective Structured Practical Examination and Traditional Practical Examination. Mymensingh Med J, 2007, Jan; 16(1): 7-11.

11. Karim A, Haque M. Assessment system in Pharmacology-Does it reflect educational objectives and community health needs? Bangladesh J Physiol Pharmacol, 1996, July, 12(2): 65-67.

12. Begum AA. A Study of the Assessment System of The MPhil (Medical Science) Anatomy Course In Bangladesh [Thesis]. Department of anatomy: Bangabandhu Sheikh Mujib medical university, Dhaka, Bangladesh; 2001.

13. Guilbert JJ. Educational Hand book for health personnel (Revised edition), WHO offset publications No. 35. Geneva: WHO; 1981. 